\title{
Cognitive Reserve: A SPECT Study of 132 Alzheimer's Disease Patients with an Education Range of 0-19 Years
}

\author{
Yi-Chu Liao ${ }^{a, c, f}$ Ren-Shyan Liu ${ }^{d}$ Evenly Lee Teng ${ }^{\text {h }}$ Yi-Chung Lee ${ }^{a, b, g}$ \\ Pei-Ning Wang ${ }^{a, c}$ Ker-Neng Lin ${ }^{c, e}$ Chih-Ping Chung ${ }^{a, c}$ Hsiu-Chih Liu ${ }^{a, c}$ \\ ${ }^{a}$ Department of Neurology and ${ }^{b}$ Institute of Clinical Medicine, National Yang-Ming University School of \\ Medicine, ${ }^{\mathrm{C}}$ Neurological Institute and ${ }^{\mathrm{d}}$ Department of Nuclear Medicine, Taipei Veterans General Hospital, and \\ e Department of Psychology, Fu Jen Catholic University, Taipei, ${ }^{f}$ Department of Neurology, E-Da Hospital and \\ I-Shou University, Kaohsiung, and ${ }^{9}$ Department of Neurology, Taichung Veterans General Hospital, \\ Taichung, Taiwan; hepartment of Neurology, University of Southern California Keck School of Medicine, \\ Los Angeles, Calif., USA
}

\section{Key Words}

Alzheimer's disease - Cognitive reserve - Education • Single photon emission computed tomography • Statistical parametric mapping

\begin{abstract}
This study examines the associations between education, cerebral perfusion, and cognitive test performance among 132 patients with Alzheimer's disease. The participants had had between 0 and 19 years of formal schooling, and had either mild or moderate dementia according to the Clinical Dementia Rating Scale. Cerebral perfusion was evaluated by the ${ }^{99 \mathrm{~m}} \mathrm{Tc}$-hexamethylpropylene amine oxime single photon emission computed tomography. The Mini-Mental State Examination and the Cognitive Abilities Screening Instrument were used to assess cognitive performance. For patients at each clinical dementia severity level, statistical parametric mapping was used to examine voxel by voxel the association between education and cerebral perfusion, and Pearson's correlation coefficients were calculated be-
\end{abstract}

tween education and cognitive test scores. Years of formal schooling had negative associations with cerebral perfusion and positive associations with cognitive test scores. The brain regions showing a significant education effect on perfusion involved bilateral posterior association areas in mild dementia, and bilateral parietotemporo-frontal areas in moderate dementia. The present findings indicate that the cognitive reserve effect starts at the low end of the education range. They also suggest that the main effect of more education is a more facile use of alternative brain circuits instead of locally increased synaptic connections.

Copyright $(2005$ S. Karger AG, Basel

\section{Introduction}

Little or no formal education is an important risk factor for dementia including Alzheimer's disease (AD) [13], and a 'cognitive reserve' hypothesis has been proposed to account for this phenomenon. In essence, this hypothesis suggests that more schooling, together with its associ-

\section{KARGER}

Fax +4161306 1234 E-Mail karger@karger.ch www.karger.com (c) 2005 S. Karger AG, Basel $1420-8008 / 05 / 0201-0008 \$ 22.00 / 0$

Accessible online at:

www.karger.com/dem
Dr. Hsiu-Chih Liu

The Neurological Institute, Taipei Veterans General Hospital

$201 \mathrm{Sec} .2$, Shih-pai Road, Shih-pai

Taipei 11217 (Taiwan)

Tel. +8862 2875 7492, Fax +88622873 8696, E-Mail hcliu@vghtpe.gov.tw 
ated conditions including more cognitively stimulating occupational and leisure activities, may result in richer synaptic connections and more facile utilization of a larger variety of alternative brain circuits for performing cognitive tasks $[4,5]$. Consequently, higher education and a more cognitively stimulating lifestyle in general can delay or lessen the clinical manifestation of the pathological advances of $\mathrm{AD}$. In other words, at comparable clinical levels of impairment, individuals with higher educational attainment have already sustained more advanced AD pathology. Consistent with this hypothesis, a lower prevalence rate [3], faster decline [6, 7], and higher mortality $[8,9]$ have been found among AD patients with higher education, and the association between cognitive functions and $\mathrm{AD}$ pathology also differed as a function of educational attainment [10].

Several functional imaging studies have shown that, at comparable dementia severity, lower perfusion or greater reduction in metabolic rate were associated with higher education among AD patients [11-13]. Since hypoperfusion or lowered metabolic rate are generally accepted to be indicators of $\mathrm{AD}$ pathology $[14,15]$, these findings also lend support to the cognitive reserve hypothesis. However, the majority of patients in these studies had at least some high school education. Therefore, it is unclear whether or not the cognitive reserve effect also extends to the lower ranges of education. In addition, these studies used cognitive test scores to indicate disease severity, but performance on cognitive tests is by itself influenced by education [16].

In the present study, we examined the association between education and cerebral perfusion among AD patients who had had between 0 and 19 years of formal schooling. To indicate dementia severity, we used ratings on the Clinical Dementia Rating (CDR) [17] scale that did not involve cognitive testing and were based on interview findings about the patients' functional level in their daily activities. For the identification of brain regions that show an education effect, we used the statistical parametric mapping (SPM) method to perform voxel-byvoxel analysis of single photon emission computed tomography (SPECT) images. The SPM method is more quantitative than visual inspection; it also avoids the limitations of the predetermined 'region of interest' approach [18]. The SPM method has been used successfully in comparing cerebral perfusion between AD patients who differed in clinical severity [19], and in identifying additional regions of hypoperfusion among $\mathrm{AD}$ patients who also had depression [20].

\section{Methods}

\section{Subjects}

The 132 participants of this study were recruited from the memory clinic of a large university-affiliated medical center. All patients at this clinic were screened for dementia and, if dementia was suspected, received further medical, neurological, neuropsychological, and psychiatric assessments. For the majority of these patients, neurological assessment included cerebral CT, or MRI, or both, in order to rule out intracranial pathology such as brain tumor or stroke that might have contributed to the cognitive decline. SPECT was not part of the routine workup.

The inclusion criteria for participation in the SPECT study were (1) a diagnosis of probable AD according to the NINCDS-ADRDA criteria (the criteria adopted by the National Institute of Neurological and Communicative Disorders and Stroke and by the Alzheimer's Disease and Related Disorders Association) [21], and (2) a rating of either 1 or 2 on the CDR scale [17, 22]. The exclusion criteria were (1) having possible additional causes of dementia as determined by history, neurological examination, imaging and blood studies; (2) an additional diagnosis of major depression or dysthymia, and (3) a lack of a responsible family member who could provide informed consent for study participation. The first criterion for exclusion helped ensure that all participants had reasonably pure AD.

\section{CDR Staging}

The CDR scale was designed to stage the severity of dementia. It assesses a patient's functional level in daily life in (1) recent and long-term memory; (2) orientation to time, place, and person; (3) judgment and problem solving; (4) community affairs; (5) home and hobby activities, and (6) personal care. The extent of cognitive impairment in each of the 6 areas is determined, and algorithms are provided for deriving an overall level of impairment that ranges from 0 (healthy) to 3 (severe) [17, 22]. CDR scores of 1 and 2 indicate 'mild' and 'moderate' dementia, respectively. A neuropsychologist, without knowledge of the patient's SPECT and cognitive test findings, assigned a rating on the CDR scale after conducting separate semistructured interviews with the patient and a knowledgeable informant.

\section{SPECT Imaging and the SPM Method}

All participants received a technetium- $99 \mathrm{~m}$ hexamethylpropylene amine oxime SPECT scan within 110 days (mean \pm SD $=$ $23.16 \pm 21.12$ days) of their CDR staging and cognitive testing. Imaging was conducted in a quiet, darkened room and started $30 \mathrm{~min}$ after the injection of a bolus of $740 \mathrm{MBq}$ technetium $99 \mathrm{~m}$ hexamethylpropylene amine oxime. A SPECT scanner (APEX-HELIX-HR, Elscint, Ltd.) was used to acquire the projection image. Image reconstruction was performed by filtered back projection using a Metz filter, and system resolution was measured to be $9.6 \mathrm{~mm}$ full width at half maximum. Correction for attenuation was made numerically with a uniform coefficient factor of $0.11 / \mathrm{cm}$. The reconstructed images were analyzed by SPM (SPM99, Wellcome Department of Cognitive Neurology, London, UK) in Matlab 6.0 (Math Works, Natick, Mass., USA) [18]. The data were transformed into a standard three-dimensional space with the Talairach coordinates [23]. The images were spatially normalized with the template image supplied by SPM99 and smoothed with an isotropic Gaussian kernel with a full width at half maximum of 
Table 1. Demographic data and cognitive test scores of the two AD patient groups that differ in clinical dementia severity

\begin{tabular}{llll}
\hline & $\begin{array}{l}\text { Mild dementia } \\
(\mathrm{n}=87)\end{array}$ & $\begin{array}{l}\text { Moderate dementia } \\
(\mathrm{n}=45)\end{array}$ & $\begin{array}{l}\text { Statistical results of } \\
\text { group comparisons }\end{array}$ \\
\hline Men, \% & 51 & 49 & $\chi^{2}=0.03, \mathrm{p}=0.85$ \\
Education, years & $8.3 \pm 5.6(0-19)$ & $8.3 \pm 6.0(0-16)$ & $t=-0.03, \mathrm{p}=0.97$ \\
$\quad 0$ & $\mathrm{n}=18$ & $\mathrm{n}=9$ & \\
$1-6$ & $\mathrm{n}=19$ & $\mathrm{n}=11$ & \\
$\quad 7-12$ & $\mathrm{n}=29$ & $\mathrm{n}=12$ & \\
13 & $\mathrm{n}=21$ & $\mathrm{n}=13$ & $t=-1.19, \mathrm{p}=0.24$ \\
Age, years & $75.0 \pm 7.2(44-89)$ & $76.6 \pm 7.1(55-88)$ & $t=0.13, \mathrm{p}<0.001$ \\
CASI score & $62.1 \pm 15.4(20-90)$ & $41.0 \pm 17.6(3-77)$ & $t=7.001$ \\
MMSE score & $18.1 \pm 5.3(7-28)$ & $11.5 \pm 5.5(1-23)$ & $t=6.63, \mathrm{p}<0.001$ \\
\hline
\end{tabular}

Figures in parentheses indicate ranges.
$12 \mathrm{~mm}$ [24]. To adjust for scan-to-scan variations, for each patient local flow rates were scaled to the mean voxel value of the cerebellum. The cerebellum activities were calculated with the template method reported by Soonawala et al. [25] who established the validity of using cerebellum as the reference region for AD patients. Although the presence of plaques and neurofibrillary tangles in the cerebellum had been reported, SPECT studies showed that the cerebellum was scintigraphically unaffected before the advanced stage of $\mathrm{AD}[26,27]$.

At each clinical severity level, voxel-by-voxel analysis of the association between education and perfusion was performed. The associations between years of formal schooling and cerebral blood flow were computed twice, once with and once without the inclusion of age, gender, and the Mini-Mental State Examination (MMSE) and Cognitive Abilities Screening Instrument (CASI) scores as confounding covariates. Locations reaching statistical significance of a corrected $\mathrm{p}$ value of $<0.05$ at the cluster level were displayed on three orthogonal projections [28]. Anatomical localization was determined according to the Talairach coordinates obtained from M. Brett's transformations (www.mrc-cbu.cam.ac.uk/ Imaging/mnispace.html).

\section{Cognitive Test Performance}

Chinese versions of the MMSE [29] and the CASI were administered and scored by research assistants who did not know the CDR stage or the SPECT findings. The CASI has more items and more refined scoring than the MMSE; it provides 9 domain scores (attention, concentration, orientation, recent memory, long-term memory, language abilities, visual construction, list-generating fluency, and abstraction and judgment) that sum to a total score of 100 [30]. Each of the 9 domain scores, as well as the CASI total score, showed significant differences between different patient groups who differed in their CDR stage [31]. Partial correlation coefficients were calculated to show the association between years of education and cognitive test performance after partialling out age and gender.

Comparison of Demographic Data and Cognitive Test Scores between the Two Patient Groups of Mild $(C D R=1)$ and

Moderate $(C D R=2)$ Dementia

Significance of group differences in mean age, education, and the MMSE and CASI scores was checked by the $t$ test. Significance of group differences in gender ratio was checked by the $\chi^{2}$ test. The SPSS software, version 11.5, was used. Statistical significance was set at the two-tailed $\mathrm{p}$ value of 0.05 .

\section{Results}

Demographic data and cognitive test scores for the mild and the moderate dementia groups are shown in table 1 . The two groups are comparable in gender ratio, education, and age. The mild dementia $(\mathrm{CDR}=1)$ group had better cognitive test scores than the moderate dementia $(\mathrm{CDR}=2)$ group.

Negative associations between years of formal schooling and cerebral perfusion were found in bilateral parietal regions and some adjacent occipital and temporal regions among patients with mild dementia, and in bilateral parieto-temporo-frontal regions among patients with moderate dementia (table 2, fig. 1). Nearly identical findings were obtained with the inclusion of age, gender, and cognitive test scores as covariates in the calculations.

Scatterplots between education and cerebral perfusion are shown in figure $2 \mathrm{a}$. In order to avoid visual clutter, at each CDR level only data at the two brain loci that showed the strongest negative associations with education are presented. No brain region showed a statistically significant positive association between education and cerebral perfusion.

In contrast, education showed statistically significant $(\mathrm{p}<0.01)$ positive associations with cognitive test scores. Scatterplots between education and cognitive test scores are shown in figure $2 \mathrm{~b}$. Also shown are partial correlation coefficients between education and test scores after partialling out age and gender. 
Fig. 1. Areas with significant negative correlations between years of education and cerebral perfusion. a Mild dementia (CDR $=1)$. $\mathbf{b}$ Moderate dementia $(\mathrm{CDR}=2)$.

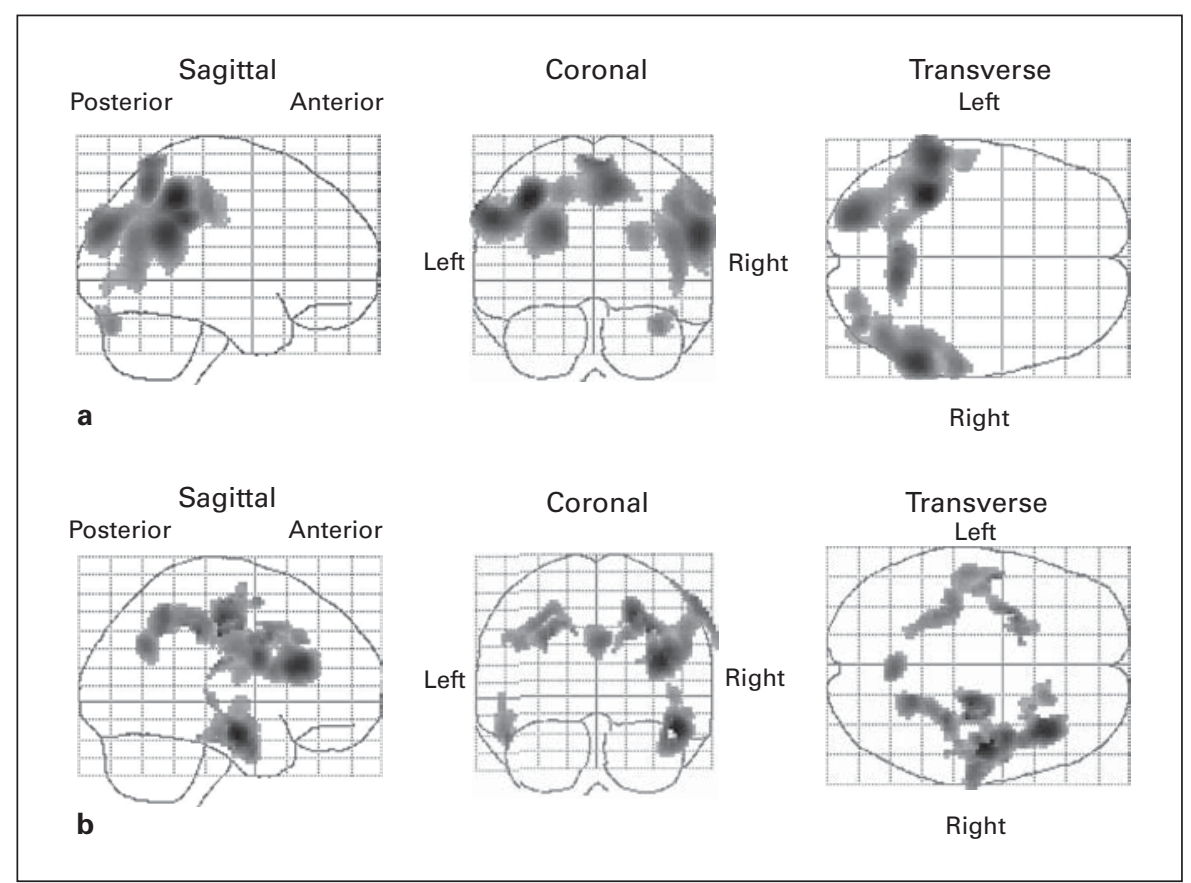

Table 2. Regions and peaks that show a significant correlation between years of education and local perfusion

\begin{tabular}{|c|c|c|c|c|c|c|c|c|c|}
\hline \multicolumn{5}{|l|}{$\mathrm{CDR}=1$} & \multicolumn{5}{|l|}{$\mathrm{CDR}=2$} \\
\hline \multirow[t]{2}{*}{ brain regions } & \multicolumn{3}{|c|}{ Talairach coordinates } & \multirow[t]{2}{*}{$\mathrm{Z}$ value } & \multirow[t]{2}{*}{ brain regions } & \multicolumn{3}{|c|}{ Talairach coordinates } & \multirow[t]{2}{*}{$\mathrm{Z}$ value } \\
\hline & $\mathrm{x}$ & $\mathrm{y}$ & $\mathrm{z}$ & & & $\mathrm{x}$ & $\mathrm{y}$ & $\mathrm{z}$ & \\
\hline Lt inferior parietal lobule & -36 & -40 & 46 & 4.51 & Lt parietal, subgyral & -30 & -27 & 44 & 3.99 \\
\hline \multirow[t]{3}{*}{ Lt occipital, cuneus } & -24 & -78 & 32 & 4.01 & Lt frontal, subgyral & -26 & 9 & 35 & 4.26 \\
\hline & & & & & Lt middle temporal gyrus & -50 & -5 & -18 & 4.10 \\
\hline & & & & & Lt superior temporal gyrus & -51 & -10 & -5 & 3.44 \\
\hline Rt parietal, supramarginal gyrus & 59 & -45 & 26 & 4.27 & Rt parietal, precuneus & 22 & -48 & 45 & 4.43 \\
\hline Rt parietal, postcentral gyrus & 61 & -21 & 40 & 3.60 & Rt parietal, postcentral gyrus & 32 & -29 & 38 & 4.46 \\
\hline \multirow[t]{3}{*}{ Rt middle temporal gyrus } & 50 & -61 & 25 & 3.64 & Rt temporal, subgyral & 46 & -10 & -16 & 5.50 \\
\hline & & & & & Rt temporal, fusiform gyrus & 44 & -3 & -23 & 4.28 \\
\hline & & & & & Rt frontal, subgyral & 38 & 24 & 17 & 5.25 \\
\hline
\end{tabular}

The scatterplots show three main points: (1) cerebral perfusion (scaled to the mean cerebellum perfusion), as well as cognitive test scores, were in general lower in moderate dementia than in mild dementia; (2) at each dementia severity level, education had negative associations with cerebral perfusion, but positive associations with cognitive test scores, and (3) the effects of education on cerebral perfusion and cognitive test scores cover the entire education range of $0-19$ years.

\section{Discussion}

This study examined cerebral perfusion and cognitive test performance of $\mathrm{AD}$ patients in relation to their educational attainment. It differed from prior studies [11-13] in that we used a larger sample size and covered a wider education range, extending its low end to include no or few years of formal schooling. In addition, we used functional level in daily life instead of cognitive test scores to indicate 

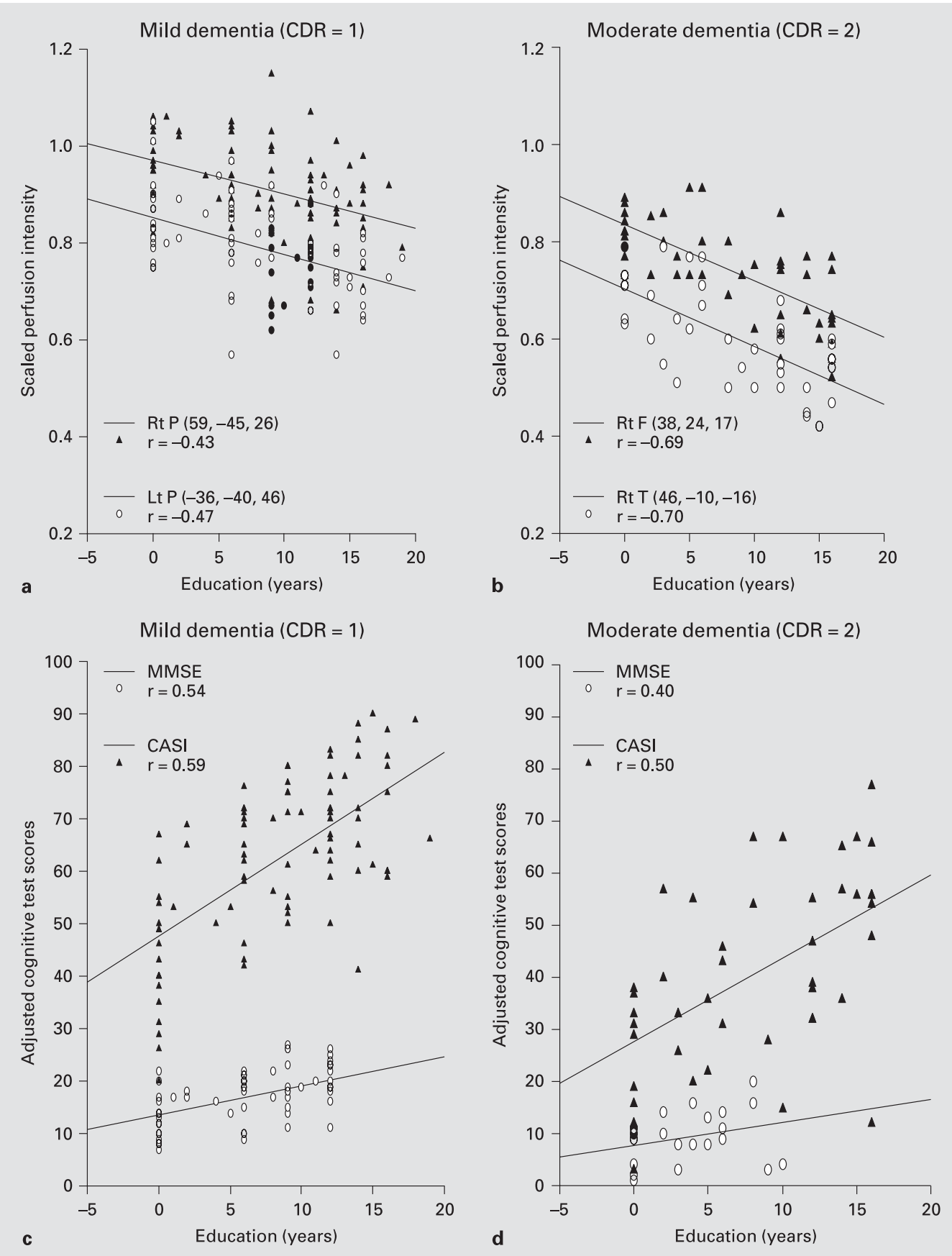

Fig. 2. a Scatterplots between years of education and scaled perfusion intensity at two locations that showed the most significant correlations. $\mathrm{F}=$ Frontal lobe; $\mathrm{P}=$ parietal lobe; $\mathrm{T}=$ temporal lobe. Numbers in parentheses are Talairach coordinates. b Scatterplots between years of education and cognitive test scores, and partial correlation coefficients between education and test scores after partialling out age and gender.

the clinical severity of dementia. The main findings were the following: (1) at each of two severity levels and throughout the education range of $0-19$ years, patients with more years of formal schooling had lower cerebral perfusion but higher cognitive test scores, and (2) the brain regions showing an education effect involved bilateral posterior association areas in mild dementia, and bilateral parieto-temporo-frontal areas in moderate dementia. 
Since cerebral hypoperfusion is generally accepted to be an indicator for AD pathology [14, 15], our first finding indicates that, despite greater $\mathrm{AD}$ pathology, patients with more education still had better cognitive test performance than, and could maintain comparable functional levels as, patients with less education. Previous studies have shown that, with comparable cognitive test scores, AD patients with higher education showed lower cerebral perfusion [11-13]. However, it is likely that individuals with more years of schooling are just more used to and apt at taking cognitive tests. In addition, since most cognitive tests are designed by academics, some test items may tap abilities (e.g. reading and writing) poorly developed by individuals who had no or few years of formal schooling. Consequently, individuals with more years of schooling will typically score higher on cognitive tests, with or without $\mathrm{AD}$, and greater $\mathrm{AD}$ pathology is needed to cancel the benefits of education on test scores. Instead of cognitive test scores, the present study used interview findings about the patients' functional level in their everyday life to indicate dementia severity. Therefore, our findings have provided stronger support for the cognitive reserve hypotheses.

Patients in previous SPECT studies had an average education level of around 15 years [11-13], and few individuals with little or no formal schooling were included. Therefore, it was unclear whether or not the cognitive reserve effect supported by their findings would extend to the low end of the education range. The present study covered an education range of $0-19$ years, and the findings are supportive of a cumulative effect of education that starts at the very low end of the education range.

The neural effect of education for cognitive reserve has been hypothesized to include either enriched synaptic connections, or a more facile use of alternative neural circuits, or both $[4,5]$. Findings from this and other SPECT studies seem to favor the second hypothesis. If the main neural effect of education was denser synaptic connections, we would have found positive associations between years of schooling and cerebral perfusion.

The exact brain sites that showed an education effect were different between the mild dementia and the moderate dementia groups, as well as between the present and previous findings [11-13]. In fact, there was no exact agreement in location between any two of the studies. For example, Stern et al. [11] identified parieto-temporal regions, Scarmeas et al. [12] identified precuneus, middle frontal gyrus, and middle temporal gyrus, and Alexander et al. [13] identified right prefrontal, bilateral premotor and left parietal association regions. These differences are attributable to the many differences among the studies in measurement and analysis methods, as well as in patient characteristics. In the SPM analysis of SPECT data, only locations that show significant perfusion differences were identified. In other words, regions that are equally poorly perfused or equally well perfused in relation to education will not be identified. Therefore, the findings are sensitively influenced by the patients' general stage of AD progression. Many PET and SPECT studies have reported that the parieto-temporal cortex is affected early in $\mathrm{AD}$ and the pathology spreads to frontal lobes with disease progression $[32,33]$. Findings in figure 1 are consistent with this trend and indicate that the pathological changes in $\mathrm{AD}$ do progress from posterior association areas towards anterior ones [34]. However, in this study we compared two groups of patients who differed in dementia severity. Our conclusions will become stronger when the findings are confirmed with longitudinal follow-up.

Impairment in recent memory is the earliest and most prominent cognitive deficit in $\mathrm{AD}$, and the hippocampi are critically important for recent memory. It may appear unexpected that our study did not find significant associations between hippocampal perfusion and education. The reason may be that, by the time a diagnosis of $\mathrm{AD}$ could be made, recent memory and hippocampal structures were already severely impaired in all participants regardless of their educational attainment, therefore no negative association between education and hippocampal perfusion was found.

To summarize, this study has provided stronger support for the cognitive reserve effect of education, has extended it to the low end of the education range, and favors a 'flexible neural circuitry' interpretation of the education effect. Finally, although years of formal schooling has been used as the explanatory variable in data analysis, it should be noted that other associated conditions including cognitively more stimulating occupations $[6,35]$ and leisure activities $[36,37]$ are also implicated.

\section{Acknowledgements}

This study was supported in part by grants from the National Science Council (NSC 92-2314-B-010-031 and NSC 92-3112-B010-004) and Taipei Veterans General Hospital (V92-310). 


\section{References}

1 Katzman R: Education and the prevalence of dementia and Alzheimer's disease. Neurology 1993;43:13-20.

-2 Stern Y, Gurland B, Tatemichi TK, Tang MX, Wilder D, Mayeux R: Influence of education and occupation on the incidence of Alzheimer's disease. JAMA 1994;271:1004-1010.

-3 Zhang MY, Katzman R, Salmon D, Jin H, Cai GJ, Wang ZY, Qu GY, Grant I, Yu E, Levy P, Klauber MR, Liu WT: The prevalence of dementia and Alzheimer's disease in Shanghai, China: Impact of age, gender and education. Ann Neurol 1990;27:428-437.

4 Mortimer JA, Graves AB: Education and other socioeconomic determinants of dementia and Alzheimer's disease. Neurology 1993;43(suppl 4):S39-S44

5 Stern Y: What is cognitive reserve? Theory and research application of the reserve concept. J Int Neuropsychol Soc 2002;8:448-460.

6 Stern Y, Albert S, Tang MX, Tsai WY: Rate of memory decline in $\mathrm{AD}$ is related to education and occupation: Cognitive reserve? Neurology 1999;53:1942-1947.

-7 Teri L, McCurry SM, Edland SD, Kukull WA, Larson EB: Cognitive decline in Alzheimer's disease: A longitudinal investigation of risk factors for accelerated decline. J Gerontol A Biol Sci Med Sci 1995;50A:M49-M55.

-8 Qiu C, Backman L, Winblad B, Aguero-Torres $\mathrm{H}$, Fratiglioni L: The influence of education on clinically diagnosed dementia incidence and mortality data from the Kungsholmen Project. Arch Neurol 2001;58:2034-2039.

-9 Stern Y, Tang MX, Denaro J, Mayeux R: Increased risk of mortality in Alzheimer's disease patients with more advanced educational and occupational attainment. Ann Neurol 1995; 37:590-595.

10 Bennett DA, Wilson RS, Schneider JA, Evans DA, Aggarwal NT, Arnold SE, Cochran EJ, Berry-Kravis E, Bienias JL: Apolipoprotein E epsilon 4 allele, $\mathrm{AD}$ pathology, and the clinical expression of Alzheimer's disease. Neurology 2003;60:246-252.

-11 Stern Y, Alexander GE, Prohovnik I, Mayeux $\mathrm{R}$ : Inverse relationship between education and parietotemporal perfusion deficit in Alzheimer's disease. Ann Neurol 1992;32:371-375.

-12 Scarmeas N, Zarahn E, Anderson KE, Habeck CG, Hilton J, Flynn J, Marder KS, Bell KL, Sackeim HA, Van Heertum RL, Moeller JR, Stern Y: Association of life activities with cerebral blood flow in Alzheimer disease: Implications for the cognitive reserve hypothesis. Arch Neurol 2003;60:359-365.

13 Alexander GE, Furey ML, Grady CL, Pietrini P, Brady DR, Mentis MJ, Schapiro MB: Association of premorbid intellectual function with cerebral metabolism in Alzheimer's disease: Implications for the cognitive reserve hypothesis. Am J Psychiatry 1997;154:165-172.
14 McGeer PL, Kamo H, Harrop R, McGeer EG, Martin WRW, Pate BD, Li DKB: Comparison of PET, MRI, and CT with pathology in a proven case of Alzheimer's disease. Neurology 1986;36:1569-1574.

15 Bradley KM, O'Sullivan VT, Soper NDW, Nagy Z, King EMF, Smith AD, Shepstone BJ: Cerebral perfusion SPET correlated with Braak pathological stage in Alzheimer's disease. Brain 2002;125:1772-1781.

16 Kittner SJ, White LR, Farmer ME, Wolz M, Kaplan E, Moes E, Brody JA, Feinleib M: Methodological issues in screening for dementia: The problem of education adjustment. J Chronic Dis 1986;39:163-170.

17 Hughes CP, Berg L, Danziger WL, Coben LA, Martin RL: A new clinical scale for the staging of dementia. Br J Psychiatry 1982;140:566572.

18 Friston KJ, Holmes AP, Worsley KJ, Poline JP, Frith CD, Frackowiak RSJ: Statistical parametric maps in functional imaging: A general linear approach. Hum Brain Mapp 1995; 2:189-210

19 Lee YC, Liu RS, Liao YC, Sun CM, Wang PS, Wang PN, Liu HC: Statistical parametric mapping of brain SPECT perfusion abnormalities in patients with Alzheimer's disease. Eur Neurol 2003;49:142-145.

20 Liao YC, Liu RS, Lee YC, Sun CM, Liu CY, Wang PS, Wang PN, Liu HC: Selective hypoperfusion of anterior cingulate gyrus in depressed AD patients: A brain SPECT finding by statistical parametric mapping. Dement Geriatr Cogn Disord 2003;16:238-244.

21 Mckhann G, Drachman D, Folstein M, Katzman R, Price D, Stadlan EM: Clinical diagnosis of Alzheimer's disease: Report of the NINCDS-ADRDA Work Group under the auspices of Department of Health and Human Services Task Force on Alzheimer's Disease. Neurology 1984;34:939-944.

22 Lin KN, Liu HC: Clinical Dementia Rating (CDR), Chinese version. Acta Neurol Taiwan 2003:12:154-165.

23 Talairach J, Tournoux P: Coplanar Stereotactic Atlas of the Human Brain: Three-Dimensional Proportional System: An Approach to Cerebral Imaging. New York, Thieme Medical, 1988.

24 Friston KJ, Ashburner J, Firth CD, Poline JB, Heather JD, Frackowiak RSJ: Spatial registration and normalization of images. Hum Brain Mapp 1995;2:165-189.

-25 Soonawala D, Amin T, Ebmeier KP, Steele JD, Dougall NJ, Best J, Migneco O, Nobili F, Scheidhauer K: Statistical parametric mapping of ${ }^{99 \mathrm{~m}} \mathrm{Tc}-\mathrm{HMPAO}$-SPECT images for the diagnosis of Alzheimer's disease: Normalizing to cerebellar tracer uptake. Neuroimage 2002;17: 1193-1202.
26 Pickut BA, Dierckx RA, Dobbeleir A, Audenaert K, Van Laere K, Vervaet A, De Deyn PP: Validation of the cerebellum as a reference region for SPECT quantification in patients suffering from dementia of the Alzheimer type. Psychiatry Res 1999;90:103-112.

27 Ishii K, Sasaki M, Kitagaki H, Yamaji S, Sakamoto S, Matsuda K, Mori E: Reduction of cerebellar glucose metabolism in advanced Alzheimer's disease. J Nucl Med 1997;38: 925-928.

28 Chetelat G, Desgranges B, de la Sayette V, Viader F, Eustache F, Baron JC: Mild cognitive impairment: Can FDG-PET predict who is to rapidly convert to Alzheimer's disease? Neurology 2003;60:1374-1377.

29 Folstein MF, Folstein SE, McHugh PR: 'Minimental state': A practical method for grading the cognitive state of patients for the clinician. J Psychiatr Res 1975;12:189-198.

30 Teng EL, Hasegawa K, Homma A, Imai Y, Larson E, Graves A, Sugimoto K, Yamaguchi T, Sasaki H, Chiu D, White LR: The Cognitive Abilities Screening Instrument (CASI): A practical test for cross-cultural epidemiological studies of dementia. Int Psychogeriatr 1994;6: $45-58$.

31 Liu HC, Teng EL, Lin KN, Chuang YY, Wang PN, Fuh JL, Liu CY: Performance on the Cognitive Abilities Screening Instrument at different stages of Alzheimer's disease. Dement Geriatr Cogn Disord 2002;13:244-248.

32 Matsuda H: Cerebral blood flow and metabolic abnormalities in Alzheimer's disease. Ann Nucl Med 2001;15:85-92.

- 33 Brown DR, Hunter R, Wyper DJ, Patterson J, Kelly RC, Montaldi D, McCulloch J: Longitudinal changes in cognitive function and regional cerebral function in Alzheimer's disease: A SPECT blood flow study. J Psychiatr Res 1996; 30:109-126.

- 34 Delacourte A, David JP, Sergeant N, Buee L, Wattez A, Vermersch P, Ghozali F, Fallet-Bianco C, Pasquier F, Lebert F, Petit H, Di Menza C: The biochemical pathway of neurofibrillary degeneration in aging and Alzheimer's disease. Neurology 1999;52:1158-1165.

- 35 Stern Y, Alexander GE, Prohovnik I, Stricks L, Link B, Lennon MC, Mayeux R: Relationship between lifetime occupation and parietal flow: Implications for a reserve against Alzheimer's disease pathology. Neurology 1995;45:55-60.

36 Wilson RS, Bennett DA, Bienias JL, Aggarwal NT, Mendes De Leon CF, Morris MC, Schneider JA, Evans DA: Cognitive activity and incident $\mathrm{AD}$ in a population-based sample of older persons. Neurology 2002;59:19101914.

37 Scarmeas N, Levy G, Tang MX, Manly J, Stern $Y$ : Influence of leisure activity on the incidence of Alzheimer's disease. Neurology 2001;57: 2236-2242. 